\title{
COVID-19 and Diabetes Mellitus: The Link and Clinical Implications
}

\author{
Chidiebere V. Ugwueze ${ }^{\text {a }}$ Basil Chukwuma Ezeokpo ${ }^{\text {a }}$ Bede I. Nnolim ${ }^{\text {a }}$ \\ Emmanuel A. Agim ${ }^{a}$ Nnamdi C. Anikpo ${ }^{a}$ Kenechukwu E. Onyekachi ${ }^{a}$ \\ aEndocrinology, Diabetes and Metabolism Unit, Department of Medicine, Alex Ekwueme Federal \\ University Teaching Hospital Abakaliki, Abakaliki, Nigeria
}

\section{Keywords}

COVID-19 · Diabetes · Link and clinical implication ·

Angiotensin-converting enzyme-2 - Dipeptidyl peptidase-4

\section{Abstract}

Background: Coronavirus disease 2019 (COVID-19) is a pandemic viral infection that has ravaged the world in recent times, and the associated morbidity and mortality have been much more pronounced in those with noncommunicable disease. Diabetes mellitus is one of commonest noncommunicable diseases associated with worsening clinical status in COVID-19 patients. Summary: The aim of this review was to evaluate the receptors and pathogenetic link between diabetes and COVID-19. Both disease conditions involve inflammation with the release of inflammatory markers. The roles of angiotensin-converting enzyme molecule and dipeptidyl peptidase were explored to show their involvement in COVID-19 and diabetes. Pathogenetic mechanisms such as impaired immunity, microangiopathy, and glycemic variability may explain the effect of diabetes on recovery of COVID-19 patients. The effect of glucocorticoids and catecholamines, invasion of the pancreatic islet cells, drugs used in the treatment of COVID-19, and the lockdown policy may impact

karger@karger.com www.karger.com/dde

Karger

BOPEN ACCESS
(C) 2020 The Author(s)

Published by S. Karger AG, Basel

This article is licensed under the Creative Commons AttributionNonCommercial-NoDerivatives 4.0 International License (CC BYNC-ND) (http://www.karger.com/Services/OpenAccessLicense) Usage and distribution for commercial purposes as well as any distribution of modified material requires written permission. negatively on glycemic control of diabetic patients. The outcome studies between diabetic and nondiabetic patients with COVID-19 were also reviewed. Some drug trials are still ongoing to determine the suitability or otherwise of some drugs used in diabetic patients with COVID-19, such as dapagliflozin trial and linagliptin trial.

(c) 2020 The Author(s)

Published by S. Karger AG, Basel

\section{Introduction}

Coronavirus disease 2019 (COVID-19) is a viral infectious disease caused by the coronavirus, severe acute respiratory syndrome coronavirus 2 (SARS-CoV-2) [1]. It is a single-stranded, enveloped RNA virus named after its crown-like surface projections seen on electron microscopy [2]. COVID-19 has similar clinical features as severe acute respiratory syndrome (SARS) and Middle East respiratory syndrome (MERS), and the viruses belong to the family Coronaviridae and of the subfamily Coronavirinae[2]. They have greater similiarities in their structural and biochemical constituents. The symptoms include fever, cough, respiratory difficulty, myalgia, gastrointestinal features, and a myriad of other symptoms. 
The disease is believed to have started in Wuhan, China, and is regarded as a zoonotic infection from the wet animal market in 2019 [3]. The mortality arising from the disease is low and occurs in the severely ill patients. Mild to moderately ill patients make up about $80 \%$ of the cases. Since the onset of the disease, the number of deaths has been on the rise [4].

Diabetes mellitus is a chronic metabolic disorder that currently affects about 422 million persons worldwide [5]. COVID-19 and diabetes are both associated with acute and chronic inflammation, respectively. Both disease conditions can impact each other in terms of clinical progression and outcome. Therefore, it becomes imperative to review studies on the effect of these diseases on each other and the pharmacological approach in the management of diabetes coexisting with COVID-19.

\section{Pathogenesis of COVID-19}

COVID-19 is a viral infectious disease with a predilection for the respiratory system. The infection is spread by respiratory droplets. The incubation period, which is the duration from the time of exposure to the development of symptoms, is 2-14 days [6]. The incubation period informs the duration of quarantine period for those who have contact with exposed victims.

Zoonotic exposure was the mode of transmission of initial cases recorded in China. However, subsequent cases were obtained through human-to-human transmission via droplets in aerosols [7]. Transmission is also possible via some hospital procedures such as bronchoscopy, endotracheal intubation, and tracheostomy.

The respiratory system is initially affected, giving rise to pneumonic changes. The binding of the coronavirus S-glycoprotein to the angiotensin-converting enzyme-2 (ACE2) receptor in the host with subsequent fusion with the cell membrane initiates the viral entry [8]. The S-glycoprotein is composed of S1 and S2 subunits which are situated on the surface spikes of the virus [9].

Furin, a protease which enhances viral entry, has been documented to be elevated in diabetic patients. The enhancement of viral entry is through the cleavage of S1 and S2 domains of the surface spike proteins [10]. Favorable factors for viral replication in the cytosol include an acidic environment and the presence of proteases such as cathepsin [11].

The inflammatory changes are initiated in the respiratory system with generation of multiple cytokines and chemokines, such as tumor necrosis factor- $\alpha$; interleukin-1, 7-10; interferon gamma; granulocyte colonystimulating factor; granulocyte-monocyte colony-stimu- lating factor; fibroblast growth factor 2; monocyte chemoattractant protein-1; and macrophage inflammatory protein 1 alpha [12]. Some laboratory features include leukocytosis in most cases, although leukopenia can also be found. Inflammatory markers such as erythrocyte sedimentation rates and C-reactive proteins were elevated in the serum of COVID-19 patients. C-reactive protein was significantly associated with the progression to severe forms of COVID-19 (OR 1.056; CI 1.025-1.089; $p<0.001)$ [13].

\section{Pathogenesis of Diabetes}

Diabetes mellitus is caused by either absolute insulin lack in type 1 diabetes or insulin resistance in type 2 diabetes [14]. Chronic hyperglycemia is the main metabolic derangement in diabetes and gives rise to glucotoxicity to body tissues with the formation of advanced glycation end products [15]. These mechanisms are responsible for the chronic complications of diabetes. Lipotoxicity also plays a role.

Acute complications of diabetes include diabetic ketoacidosis (DKA) and hyperglycemic hyperosmolar states [16]. Hypoglycemia is a complication of treatment which is mainly noted with insulin or sulfonylurea use. The commonest precipitating factor in DKA and hyperglycemic hyperosmolar states is infection which increases the body's insulin requirements resulting in uncontrolled hyperglycemia. Chronic hyperglycemia predisposes to infections and the latter also worsen hyperglycemia, thus initiating a vicious cycle [17].

The role of inflammation in diabetes has been described. The association between inflammation and diabetes was made based on the identification of inflammatory markers such as C-reactive proteins, IL-6, plasminogen activator inhibitor-1, tumor necrosis factor- $\alpha$, leptin, and adiponectin $[18,19]$.

\section{Interrelationship between Diabetes and COVID-19}

Infection at Receptor Level

Dipeptidyl Peptidase-4

Incretins such as glucagon-like peptide and gastric inhibitory peptide are known to be defective in type 2 diabetic patients. They enhance insulin secretion. However, these incretins can be degraded by dipeptidyl peptidase- 4 (DPP4) in the intestinal tract, thus potentially reducing their activities. DPP4 is a transmembrane glycoprotein which exists as a dimer in active state and has a molecular mass of $220 \mathrm{kDa}$ [20]. DPP4 inhibitors inhibit the activity of this degrading enzyme, thus enhancing the capacity of incretins in insulin secretion. They include
Ugwueze/Ezeokpo/Nnolim/Agim/ Anikpo/Onyekachi 
vildagliptin, saxagliptin, sitagliptin, linagliptin, teneligliptin, and trelagliptin [21].

This same enzyme has been implicated as a component of an entry receptor for the coronaviruses: human coronavirus-Erasmus Medical Center [22] and MERSCoV [23]. DPP4 was originally referred to as CD26 [20]. However, the site of DPP4 in coronavirus pathogenesis is located in the bronchial tree [22]. Human coronavirusErasmus Medical Center has genetic resemblance to other coronaviruses.

In an animal study by Iwata Yoshikawa et al. [24], transgenic mouse models were made susceptible to MERS-CoV by expressing DPP4. Type 2 diabetes was induced in the mice using high-fat diet. The DPP4 mice fed with high-fat diet developed hyperglycemia and hyperinsulinemia (which are the initial stages in the pathogenesis of type $2 \mathrm{DM}$ ). When the DPP4 mice were infected with MERS-CoV, they had severe viral infection with delayed recovery and weight loss which were independent of viral titers [25].

Since MERS-CoV and SARS-CoV-2 belong to the same subfamily of Coronavirinae, it is possible that the effect of diabetes on the viral infections may be similar. This requires elucidation from future research works.

Does the above implication mean better efficacy of DPP4 inhibitors in diabetic patients with COVID-19? A clinical trial (NCT04341935) is ongoing with the aim of determining the efficacy of linagliptin in diabetes control and reduction in the severity of COVID-19 infection [26]. The primary completion date is October 30, 2020.

\section{ACE2 Receptor}

ACE2 receptor is very vital in SARS-CoV-2 entry into the cells. The receptor is sufficiently expressed by the epithelial cells of the lungs, intestine, kidney, and vessels [27]. Li et al. [28] showed that patients with diabetes also express high concentrations of ACE2 and its level is significantly raised in those taking angiotensin-converting enzyme inhibitors (ACEi) or angiotensin receptor blockers (ARBs). The hypothesis that ACE2 polymorphisms are linked to some noncommunicable diseases such as diabetes, hypertension, stroke, and genetic predisposition to developing SARS-CoV 2 infection has been postulated $[29,30]$.

SARS-CoV-2 infectivity is related to the rate of shedding of ACE2. Lambert et al. [31] showed that A disintegrin and metalloproteinase 17 (ADAM17) is capable of shedding the ecto-domains of some membrane-bound cell adhesion molecules and cytokines such as ACE2 molecule. The extracellular domain of ACE2 forms the recep-

COVID-19 and Diabetes Mellitus:

The Link and Clinical Implications tor for the spike (S) protein of SARS-CoV-2, and this is the basic site for the pathogenesis of SARS-CoV-2 infection [32]. This was demonstrated using phorbol myristate acetate, which caused the transformation of ACE2 with a molecular weight of $120 \mathrm{kDa}$ to a polypeptide of $105 \mathrm{kDa}$ and the proteolytic shedding of the ACE2 enzymatic active ecto-domain [31]. Thus, inhibition of ADAM17 results in the reduction of proteolytic shedding of the ACE2 ecto-domain and eventually increases the rate of entry and infectivity of SARS-CoV-2 [33]. The finding is from laboratory animals but yet to be replicated in humans. The inhibitors of ADAM17 include tissue inhibitory metalloproteinase- 3 and insulin $[34,35]$. Another protease, transmembrane protease serine 2 antagonizes the effect of ADAM17 and enhances the cellular uptake of soluble SARS-CoV2 entry through the cleavage of ACE2 [36].

\section{ACEi and ARBs}

ACEi and ARBs are important antihypertensive medications that are widely used in patients with hypertension and diabetes. They are known to increase cardiac ACE2 [37]. In view of the role of ACE2 in COVID-19 pathogenesis, it is important to detect effects of these drugs on the severity of the disease. Most authors still hold the opinion that despite the theoretical knowledge of increased ACE2 with ACEi or ARBs, there is not enough practical evidence from large population studies to refute their use in patients with hypertension and diabetes [38, 39]. Chen et al. [40] showed that the clinical outcomes in COVID-19-positive patients with coexisting diabetes and hypertension who use ACE inhibitor or angiotensin II receptor blocker were comparable to those not using the drugs.

A clinical trial (NCT04318418) was designed to determine the effect of ACE inhibitors and angiotensin II type 1 receptor blockers on the severity of COVID-19 infection [41]. It was a retrospective case-control study with a target study population of 5,000 participants. The study was completed on April 30, 2020, but the outcome is not yet published.

\section{Effect of Diabetes on COVID-19 Infections}

Patients with diabetes mellitus have increased predisposition to viral and bacterial infections including those affecting the respiratory tract [42]. One of the mechanisms responsible for this predisposition is the "lazy" leukocyte syndrome, which represents impaired leukocyte function of phagocytosis (impaired immunity). This further emphasizes the likelihood of increased propensity of SARS-CoV-2 infections in diabetic cohorts [43].

Dubai Diabetes Endocrinol J 2020;26:69-77 DOI: $10.1159 / 000511354$ 
Microangiopathy in diabetes mellitus also impairs the lung compliance with consequent affectation of the gaseous exchange. This impairment may result in the proliferation of some respiratory pathogens including SARSCoV-2 [44]. There are respiratory changes in diabetic patients that affect lung volumes and pulmonary diffusing capacity [45].

Muniyappa and Gubbi [43] summarized the potential mechanisms through which diabetes increases the SARSCoV-2 morbidity and mortality: (i) increased cellular binding affinity and efficient viral entry, (ii) decreased viral clearance, (iii) reduced $\mathrm{T}$-cell function, and (iv) increased susceptibility to hyper-inflammation and cytokine storm. In the present COVID-19 pandemic, a study done in Italy showed that diabetes mellitus ranks high among the comorbidities in patients with COVID-19. Systemic hypertension and ischemic heart disease were also common among the comorbidities noted in the patients [46].

A study done in Wuhan on the characteristics of COVID-19 patients showed that patients with diabetes mellitus accounted for $2-20 \%$ of positive cases and also constituted about $7.1 \%$ of ICU admissions [12]. Yang et al. [47] and Cheng et al. [48] also demonstrated a prevalence of 17 and $12.1 \%$, respectively, among 52 and 99 coronavirus-positive cases in China. However, some parameters such as glycated hemoglobin and the presence of chronic diabetic complications were not reported.

A similar study done in New York among 5,700 hospitalized patients with COVID 19 showed that 1,808 patients $(33.8 \%)$ were diabetic, 3,026 (56.6\%) had systemic hypertension, while 1,737 (41.7\%) were obese [49]. This study generally emphasized the impact of noncommunicable diseases on COVID-19 infection.

Glycemic variability is a prognostic factor in diabetic patients with COVID-19 infection. Hyperglycemia worsens the outcome by the process of cytokine storm, endothelial dysfunction, and multiple organ injuries [50]. In the lungs, the primary target of COVID-19, hyperglycemia leads to a rapid deterioration in spirometric functions, especially decreased forced expiratory volume in 1 second and forced vital capacity [51]. Phillips et al. [52] showed that in hyperglycemic states, there is elevated glucose concentration in the respiratory epithelium which may affect its innate immune capacity. Hypoglycemia also increases cardiovascular mortality by accentuating monocytes which are pro-inflammatory and enhancing platelet aggregation [53]. Severe hypoglycemia which may occur with strict glycemic control may worsen the overall mortality rate [54].
Bode et al. [55] demonstrated that suboptimal glycemic control in COVID-19 patients is correlated with higher mortality rate. The mortality was $28.8 \%$ in the diabetic group compared to $6.2 \%$ in the nondiabetic group.

\section{Effect of COVID-19 on Diabetes}

COVID-19 infection compounds the stress of diabetes mellitus by releasing glucocorticoids and catecholamines into circulation. These worsen glycemic control and increase the formation of glycation end products in many organs and worsen prognosis [56].

\section{Does COVID-19 Have Any Direct Effect on the}

Pancreas?

Some authors have considered the rapidity of worsening glycemic control in stable diabetic patients with COVID-19 requiring the use of high insulin dose and suggested the possibility of pancreatic invasion by the SARSCoV-2 [57, 58]. The above perspective has been supported by the finding of high levels of ACE2 in the pancreatic islet beta cells which may cause increased islet cell injury and impaired insulin secretion [59]. Wang et al. [60] demonstrated that 9 (17\%) of 52 admitted patients in Wuhan with COVID-19 pneumonia developed pancreatic injury as evidenced by abnormality in serum amylase or lipase levels. Six of the affected 9 patients with pancreatic injury also developed glucose intolerance. After viral entry into the beta cells, there is a downregulation of ACE2 leading to increased angiotensin level, which also impairs insulin secretion [61]. Possible mechanisms of pancreatic injury include (i) direct cytopathic effect of SARS-CoV-2 replication, (ii) systemic response to respiratory failure, and (iii) harmful immune response induced by SARS-CoV-2 infection [60].

\section{Effect of Corticosteroids}

Corticosteroids such as hydrocortisone are used to suppress inflammation. In severe cases, methylprednisone (in the dose of $1-2 \mathrm{mg} / \mathrm{kg} / \mathrm{day}$ ) is used to control cytokine storm [62]. However, results showed no specific benefit but some complications such as worsening diabetes, avascular necrosis, and psychosis [63]. The use of corticosteroids may raise blood glucose by $80 \%$ in diabetic patients with COVID-19 infection and to a lesser extent in those without diabetes [64]. This has resulted in increased mortality in patients with coronavirus infection. In conditions where corticosteroids are needed, then blood glucose monitoring is vital to maintain near euglycemia and achieve optimal pulmonary and immunologic functions [65].
Dubai Diabetes Endocrinol J 2020;26:69-77 DOI: $10.1159 / 000511354$
Ugwueze/Ezeokpo/Nnolim/Agim/ Anikpo/Onyekachi 


\section{Lockdown}

A policy was implemented in many countries in a bid to flatten the infective curve of COVID-19. The effect of such policy led to limited access of many diabetic patients to their diets, exercise, drugs, and routine hospital checkup. This resulted in worsening glycemic control with eventual development of acute and chronic complications of diabetes [66].

\section{Outcome Studies of Type 2 Diabetic and Nondiabetic}

Population with COVID-19 Infection

The degree of inflammatory response to COVID-19 is more marked in diabetic patients than in nondiabetic cohorts. The study by Zhu et al. [67] showed that type 2 diabetic group had higher levels of inflammatory markers such as C-reactive protein and procalcitonin (57.0 and $33.3 \%$ ) than the nondiabetic group (42.4 and 20.3\%), respectively. Elevated C-reactive protein may serve as a marker for identifying those with high risk of death from COVID-19 [40]. The D-dimer which is a marker of coagulation status was also elevated in the diabetic group compared to the nondiabetic group ( 50.5 vs. $33.3 \%$ ). The levels of these inflammatory markers have been correlated with the severity of COVID-19 infection [68].

A derivation from the higher degree of inflammation and coagulation in diabetic-COVID patients shows that they required more integrated and intensive management than the control group. In the study at Hubei in China, among 952 participants with pre-existing type 2 diabetes, noninvasive ventilation was employed in $10.2 \%$ of diabetic patients as against $3.95 \%$ in the nondiabetic group [67]. Similarly, invasive ventilation was used in $3.6 \%$ of the diabetic group compared to $0.7 \%$ in the nondiabetic group.

The COVID-19 and Diabetes Outcomes (CORONADO) study (NCT04324736) in France was a prospective observational trial aimed at determining the phenotypic characteristics of diabetic patients admitted for COVID-19 infection [69]. The study findings showed that among 1,317 participants, $382(29 \%)$ required tracheal intubation or died within 7 days on admission, while $18 \%$ were discharged. Only BMI was independently associated with severity of COVID-19, while HbA1C, use of reninangiotensin-aldosterone system blockers, and DPP4 inhibitors were not. Other variables such as age and microvascular and macrovascular diabetic complications were associated with risk of early death. The impact of obesity on the frequency of use of mechanical ventilation was also demonstrated by Simonnet et al. [70].

\section{Does COVID Infection Affect the Choice of}

Antidiabetic Drugs?

The ideal antidiabetic medications used in DM patients with coexisting COVID-19 infection should not only lower blood glucose but should also not worsen the prognosis of COVID-19 infection. There is paucity of data on the ideal antidiabetic medication in COVID-19 patients with diabetes. Some findings concerning antidiabetic medications are discussed below.

\section{Insulin}

Insulin exhibits inhibitory action on ADAM-17 [35]. ADAM-17 enhances the proteolytic shedding of the enzymatic active ecto-domain of ACE2 in laboratory animals [31]. This may suggest that insulin increases the activity of ACE2 [35] and also increases the infectivity of SARS-CoV-2 but is yet to be substantiated in humans. The beneficial effect of insulin may be related to its antiinflammatory effect, which is by suppression of pro-inflammatory cytokines and increased immune mediators [71]. Sardu et al. [72] showed that insulin use achieved better glycemic control in 25 diabetic patients with COVID-19, where the mean glycemia during hospitalization was $10.65 \pm 0.84$ and $7.69 \pm 1.85 \mathrm{mmol} / \mathrm{L}$ in non-insulinand insulin-treated groups, respectively $(p<0.001)$ [73]. Posttreatment plasma glucose was still significantly lower in the insulin-treated group $(p<0.001)$. Recommendation by a body of experts is that insulin should be used in diabetic patients with COVID-19, especially hospitalized patients [58]. In order to reduce exposure of health-care workers to coronavirus, the use of continuous glucose monitoring has been effectively utilized [73].

Conversely, a recent study by Chen et al. [40] among 136 (120) diabetic patients of 904 clinically diagnosed COVID patients showed that insulin users compared to non-insulin users in the diabetic cohort were associated with poor prognosis (OR 3.58; 95\% CI 1.37-9.35; $p=$ 0.009). The finding of Chen et al. [40] requires validation from further meta-analytical studies.

\section{Metformin}

I. The ACE2 receptor is very vital in SARS-CoV-2 entry into the cells. Phosphorylation of the receptor renders it nonfunctional. Metformin can achieve the phosphorylation of ACE2 receptor via activation of adenosine monophosphate kinase [74]. The resultant effect is reduction in the binding capacity of the virus due to steric hindrance by incorporation of PO4-3 molecule.

Once the entry of the virus is established, there is a downregulation of ACE2 receptor and a corresponding 
Table 1. Summary of clinical trials in COVID-19 and diabetes disease states

\begin{tabular}{lllll}
\hline S/N & Phase & Primary outcome & Clinical trial ref $\begin{array}{l}\text { Completion } \\
\text { date }\end{array}$ \\
\hline CORONADO study [67] & $\begin{array}{l}\text { Noninter- } \\
\text { ventional }\end{array}$ & $\begin{array}{l}\text { Assess the prevalence of severity among hospitalized } \\
\text { patients with DM and COVID-19 }\end{array}$ & $\begin{array}{c}\text { NCT04324736 } \\
\text { May 8, } \\
2020\end{array}$ \\
\hline DARE-19 study [77] & Phase 3 & $\begin{array}{l}\text { Evaluate the effects of dapagliflozin versus placebo on } \\
\text { the risk of death/disease progression in COVID-19 } \\
\text { hospitalized patients }\end{array}$ & D1690C00081 & $\begin{array}{l}\text { December } \\
2020\end{array}$ \\
\hline CODIV-ACE study [39] & $\begin{array}{l}\text { Observational } \\
\text { study }\end{array}$ & $\begin{array}{l}\text { Severity of pneumonia or acute respiratory distress } \\
\text { syndrome by COVID-19 }\end{array}$ & NCT04318418 & $\begin{array}{l}\text { April 30, } \\
\text { 2020 }\end{array}$ \\
\hline $\begin{array}{l}\text { DPP4-inhibition on } \\
\text { COVID-19 [26] }\end{array}$ & Phase 4 & $\begin{array}{l}\text { Changes in blood glucose levels from baseline to 2 } \\
\text { weeks }\end{array}$ & NCT04341935 & December 30, \\
2020
\end{tabular}

COVID-19, coronavirus disease 2019; DPP4, dipeptidyl peptidase-4.

activation of renin-angiotensin-aldosterone system, which is responsible for the cardiac and pulmonary complications of COVID-19 infection [75]. Since metformin inhibits the viral entry into the cell by disruption of binding capacity, it may be considered beneficial in COVID-19 infection.

II. Inhibition of mammalian target of rapamycin (mTOR). Metformin inhibits mTOR via activation of adenosine monophosphate kinase in the liver and liver kinase B1. mTOR plays a significant role in the pathogenesis of influenza viruses, but this has not been documented in COVID-19 [74].

However, despite these beneficial mechanisms at the molecular levels, metformin is not recommended in the clinical management of COVID-19 infection. This is due to the risk of lactic acidosis, which may ensue in diabetic patients with dehydration from acute viral infection [58] and worsen hyperglycemic emergencies in hospitalized patients. Worsening dehydration may also result in prerenal acute kidney injury.

\section{Sulfonylureas}

Due to poor caloric intake in acute infections, the use of sulfonylureas may induce hypoglycemia. It is not ideal in the management of hyperglycemia in COVID-19 [76]. This is the case especially in ICU admissions.

\section{Glucagon-Like Peptide-1 Agonists}

Liraglutide enhances ACE2 levels in cardiac and pulmonary tissues of rats [77]. However, similar effect is not replicated in humans. Although there may be possibility of a poor outcome from its usage, this is yet to have a practical significance.
Thiazolidinediones

Pioglitazone has been shown to reduce the level of ADAM-17 in human skeletal muscles [78]. The drug also potentiates the effect of ACE2 which was noticed in rats [79]. The tendency to cause fluid retention and worsen heart failure makes pioglitazone unsuitable in patients with both diabetes and COVID-19.

\section{DPP4 Inhibitors}

The anti-inflammatory property of DPP4 inhibitors may mitigate the effect of COVID-19 on glycemic control. They do not potentiate ACE levels in mice, and thus may be considered beneficial in diabetic patients with COVID-19. Bornstein et al. [58] recommended this class of drug in treating hyperglycemia in COVID-19 patients. A clinical trial is ongoing to determine the efficacy of linagliptin in COVID-19 patients with diabetes [26]. A summary of trial with linagliptin is shown in Table 1 .

Sodium Glucose Transporter-2 Inhibitors

Sodium glucose transporter (SGLT)-2 inhibitors enhance renal ACE2 [80] and thus may have poor outcomes, but this is yet to be substantiated in randomized controlled trials. A clinical trial (DARE-19) at phase 3 is ongoing with the aim of assessing the potential of the SGLT-2 inhibitor dapagliflozin to reduce COVID-19 infection, complications, and death among adults with cardiovascular, metabolic, and renal risk factors [81]. This is shown in Table 1. Dehydration and euglycemic DKA are limiting factors to the use of SGLT-2 inhibitors [58].
Dubai Diabetes Endocrinol J 2020;26:69-77 DOI: $10.1159 / 000511354$
Ugwueze/Ezeokpo/Nnolim/Agim/ Anikpo/Onyekachi 
Chloroquine/Hydroxychloroquine

The mechanism responsible for the hypoglycemic effect of chloroquine is not clearly elucidated [82]. However, improvement in the pancreatic beta cell function has been suggested as shown by increased C-peptide response when the drug is administered [83]. Kumar et al. [84] evaluated the efficacy and safety of hydroxychloroquine when added to stable insulin therapy in combination with metformin and glimepiride in comparison to sitagliptin. After a study period of 24 weeks, $\mathrm{HbA1C}$ reduction was $1.3 \%$ in the hydroxychloroquine group and $0.9 \%$ in the sitagliptin group $(p<0.001)$. A greater reduction in fasting plasma glucose of $31.0 \mathrm{mg} / \mathrm{dL}$ in the hydroxychloquine group than $23.2 \mathrm{mg}$ in the sitagliptin group was observed. The study, however, did not specify whether the participants in the hydroxychloroquine group developed side effects of hydroxychloroquine such as retinal impairment, skin reaction, hearing loss, and cardiac arrhythmias, which are notable limitations to its use in diabetes [85].

The mechanism of action of hydroxychlorquine is by increasing the $\mathrm{pH}$ of intracellular milieu which inhibits insulin breakdown, thus enhancing its recirculation and effectiveness in hyperglycemic states [86]. However, chloroquine or hydroxychloroquine is not classified as a typical antidiabetic drug. Hydroxychloroquine is also one of the experimental drugs used in COVID patients. It is used in conjunction with zinc to improve its efficacy [87]. Cheng et al. [40] showed in a multivariate regression analysis that the typical antidiabetic drugs (insulin, secretagogues, metformin, DPP4 inhibitors, and alpha-glycosidase inhibitors) were not associated with in-hospital mortality.

\section{Conclusion}

The knowledge of interaction between diabetes and COVID-19 is still evolving. However, some clearly established links include the role of ACE2 and increased severity of COVID-19 infection in patients with diabetes. The role of DPP4 is implicated in MERS-CoV pathogenesis, so theoretically it may be implicated in SARSCoV2 also, as they belong to the same subfamily and family. Inflammation has been implicated in both disease conditions.

Although some antidiabetic drugs have effects on the cellular entry molecules, randomized controlled trials have not established worsening of diabetes control with these drugs in COVID-19 infection. Antidiabetic drugs that can reduce inflammatory processes and achieve good glycemic control are ideal. Insulin is of special importance in managing COVID-19 patients with diabetes, especially those who have hyperglycemic emergencies or in ICU admission. More elaborate research and randomized control trials are still required to elucidate some unclear postulates regarding the molecular and therapeutic interrelationship between diabetes and COVID-19 infection.

\section{Conflict of Interest Statement}

The authors declare that they have no conflicts of interest to disclose.

\section{Funding Sources}

This research did not receive any specific grant from funding agencies in the public, commercial, or not-for profit sectors.

\section{Author Contributions}

C.V.U. and B.C.E.: conceptualization, literature search, and writing of the manuscript. B.I.N., E.A.A., N.C.A., and K.E.O.: literature search, analysis, and editing of the manuscript. All the authors have read and agreed to the final version of the manuscript.

\section{References}

1 Rothan HA, Byrareddy SN. The epidemiology and pathogenesis of coronavirus disease (COVID-19) outbreak. J Autoimmun. 2020;109: 102433.

2 Poutanen SM. Etiologic agents of infectious diseases. In: Long SS, editor. Principles and practice of paediatric infectious diseases. 4th ed. 2012. p. 1547-712.
3 Bogoch A, Watts A, Thomas-Bachli C, Huber MUG, Kraemer K. Pneumonia of unknown aetiology in Wuhan, China: potential for international spread via commercial air travel. J Trav Med. 2020;10:1093.

4 Report of the WHO-China Joint Mission on Corona Virus Disease 2019 (COVID-19) [Online]. Available from: https://www.who. int [Accessed 2020 Jun 9].
5 Diabetes- World Health Organisation [Online]. Available from: https://www.who.int/ health-topics/diabetes [Accessed 2020 May 30].

6 Management of patients with confirmed 2019-nCoV [Online]. Available from: https:// www.cdc.gov [Accessed 2020 May 25].
COVID-19 and Diabetes Mellitus:

The Link and Clinical Implications
Dubai Diabetes Endocrinol J 2020;26:69-77 DOI: $10.1159 / 000511354$ 
7 Mode of transmission of virus causing COVID 19: implications for IPC precaution recommendations. Scientific brief [Online]. Available from: who.int/news-room/commentaries [Accessed 2020 May 26].

8 Wan Y, Shang J, Graham R, Baric RS, Li F. Receptor recognition by novel coronavirus from Wuhan: an analysis based on decadelong structural studies of SARS. J Virol. 2020; 94(7): $\mathrm{e} 00127-20$.

9 Hulswit RJ, de Haan CA, Bosch BJ. Coronavirus spike protein and tropism changes. Adv Virus Res. 2016;96:29-57.

10 Fernandez C, Rysä J, Almgren P, Nilsson J, Engström G, Orho-Melander M, et al. Plasma levels of the proprotein convertase furin and incidence of diabetes and mortality. J Intern Med. 2018;284(4):377-87.

11 Guo Y, Cao Q, Hong Z. The origin, transmission, and clinical therapies on corona virus disease 2019 (COVID-19) outbreak-an update on the status. Mil Med Res. 2020;7(1):11.

12 Huang C, Wang Y, Li X, Ren L, Zhao J, Hu Y, et al. Clinical features of patients infected with 2019 novel coronavirus in Wuhan, China. Lancet. 2020;395(10223):497-506.

13 Gupta S. Elevated level of C-reactive protein may predict risk for worsening COVID-19. Infectious disease advisor. 2020 May 15.

14 Standards of Medical care in diabetes-2019. Diabetes Care. 2019;2(Suppl 1).

15 Yang P, Feng J, Peng Q, Liu X, Fan Z. Advanced glycation end products: potential mechanism and therapeutic target in cardiovascular complications under diabetes. Oxid Med Cell Longev. 2019 Dec 6;2019:9570616.

16 Gosmanov AR, Gosmanova EO, Kitabchi AE. Hyperglycemic crises: diabetic ketoacidosis (DKA), and hyperglycemic hyperosmolar state (HHS) [updated 2018]. In: Feingold KR, Anawalt B, et al., editors. Endotext [Internet]. South Dartmouth, MA: MD Text.com, Inc.; 2000.

17 Carey IM, Critchley JA, Dewilde S, Harris T, Hosking FJ, Cook DG. Risk of infection in type 1 and type 2 diabetes compared with the general population: a matched cohort study. Diabetes Care. 2018;41(3):513-21.

18 Duncan BB, Schmidt MI, Pankow JS, Ballantyne CM, Couper D, Vigo A, et al. Low grade systemic inflammation and the development of type 2 diabetes: the atherosclerosis risk in communities study. Diabetes. 2003;52(7):1799-805.

19 Kengne AP, Batty GD, Hammer M, Stamatakis $\mathrm{E}$, Czernichow S. Association of C-reactive with cardiovascular disease mortality according to diabetes status: pooled analyses of 25, 979 participants from four U.K prospective cohort studies. Diabetes Care. 2012;35:396-403.

20 Nistala R, Savin V. Diabetes, hypertension, and chronic kidney disease progression: role of DPP4. Am J Physiol Renal Physiol. 2017; 312(4):F661-70.

21 FDA Drug safety communication: FDA warns that DPP-4 inhibitors for type 2 diabetes may cause joint pain [Online]. Accessed 2020 May 20.
22 Raj VS, Mou H, Smits SL, Dekkers DH, Müller MA, Dijkman R, et al. Dipeptidyl peptidase 4 is a functional receptor for the emerging human coronavirus-EMC. Nature. 2013; 495(7440):251-4.

23 Iacobellis G. Covid 19 and Diabetes: can DPP4 inhibition play a role? Diabetes Res Clin Pract. 2020;162:108125.

24 Iwata-Yoshikawa N, Okamura T, Shimizu Y, Kotani O, Sato H, Sekimukai H, et al. Acute respiratory infection in human dipeptidyl peptidase 4-transgenic mice infected with middle East respiratory syndrome coronavirus. J Virol. 2019;93(6):e01818-18.

25 Kulcsar KA, Coleman CM, Beck SE, Frieman MB. Comorbid diabetes results in immune dysregulation and enhanced disease severity following MERS-CoV infection. JCI Insight. 2019;4(20):131774.

26 Iacobellis G. Phase 4 clinical trial. Effects of DPP4 inhibition on COVID 19 patients with type 2 diabetes. Completion date: 2020 Oct 30 (NCT04341935). Retrieved from: https/: clinicaltrials.gov.

27 Wan Y, Shang J, Graham R, Baric RS, Li F. Receptor recognition by novel coronavirus from Wuhan: an analysis based on decadelong structural studies of SARS. J Virol. 2020 Mar 17;94(7):e00127.

28 Li XC, Zhang J, Zhuo JL. The vasoprotective axes of the renin-angiotensin system: physiological relevance and therapeutic implications in cardiovascular, hypertensive and kidney diseases. Pharmacol Res. 2017;125(Pt A): 21-38.

29 European Societies of Cardiology. Position statement of ESC Council on Hypertension on ACE-inhibitors and angiotensin receptor blockers. March 13, 2020 [Online]. Accessed 2020 May 16.

30 Liu C, Li Y, Guan T, Lai Y, Shen Y, Zeyaweiding A, et al. ACE2 polymorphisms associated with cardiovascular risk in Uygurs with type 2 diabetes mellitus. Cardiovasc Diabetol. 2018;17(1):127.

31 Lambert DW, Yarski M, Warner FJ, Thornhill P, Parkin ET, Smith AI, et al. Tumor necrosis factor- $\alpha$ convertase (ADAM17) mediates regulated ectodomain shedding of severe acute respiratory syndrome-coronavirus (SARS-CoV) receptor, angiotensin-converting enzyme-2 (ACE2). J Biol Chem. 2005;280(34):30113-9.

32 Du L, He Y, Zhou Y, Liu S, Zheng BJ, Jiang S. The spike protein of SARS-CoV: a target for vaccine and therapeutic development. Nat Rev Microbiol. 2009;7(3):226-36.

33 Palau V, Riera M, Soler MJ. ADAM17 inhibition may exert a protective effect on COVID 19. Nephrol Dial Transplant. 2020:35(6):1-2.

34 Cesaro A, Abakar-Mahamat A, Brest P, Lassalle S, Selva E, Filippi J, et al. Differential expression and regulation of ADAM17 and TIMP3 in acute inflamed intestinal epithelia. Am J Physiol Gastrointest Liver Physiol. 2009; 296(6):G1332-43.

35 Salem ES, Grobe N, Elased KM. Insulin treatment attenuates renal ADAM17 and ACE2 shedding in diabetic Akita mice. Am J Physiol Renal Physiol. 2014;306(6):F629-39.

36 Heurich A, Hofmann-Winkler H, Gierer S, Liepold T, Jahn O, Pöhlmann S. TMPRSS2 and ADAM17 cleave ACE2 differentially and only proteolysis by TMPRSS2 augments entry driven by the severe acute respiratory syndrome coronavirus spike protein. J Virol. 2014;88(2):1293-307.

37 Ferrario CM, Jessup J, Chappell MC, Averill DB, Brosnihan KB, Tallant EA, et al. Effect of angiotensin-converting enzyme inhibition and angiotensin II receptor blockers on cardiac angiotensin-converting enzyme 2 . Circulation. 2005;111(20):2605-10.

38 Sommerstein R, Kochen MM, Messerli FH, Grani C. Coronavirus disease 2019 (COVID 19): do angiotensin converting enzyme inhibitors/angiotensin receptor blockers have a biphasic effect. J Am Heart Assoc. 2020;9(7): e016509.

39 HFSA/ACC/AHA Statement Addresses Concerns Re: using RAAS antagonists in COVID 19 [Online]. Accessed 2020 May 16.

40 Chen Y, Dong Y, Biao C, Jiang C, Anlin P, Yang C, et al. Clinical characteristics and outcomes of patients with diabetes and COVID-19 in association with glucose-lowering medication. Diabetes Care. 2020:43(7):1399407.

41 Castelnuovo AD, Iacoviello L. ACE inhibitors, angiotensin II type I receptor blockers and severity of COVID 19

42 Badawi A, Ryoo SG. Prevalence of diabetes in the 2009 influenza A (H1N1) and the Middle East respiratory syndrome coronavirus: a systematic review and meta-analysis. J Public Health Res. 2016;5(3):733-9.

43 Muniyappa R, Gubbi S. COVID-19 pandemic, corona viruses, and diabetes mellitus. Am J Physiol Endocrinol Metab. 2020;318(5): E736-41.

44 Ardigo D, Valtuena S, Zavaroni I, Baroni MC, Delsignor R. Pulmonary complications of diabetes mellitus: the role of glycemic control. Curr Drug Targets Inflamm Allergy. 2004; 3(4):455-8.

45 Fuso L, Pitocco D, Antonelli-Incalzi R. Diabetic lung, an underrated complication from restrictive functional pattern to pulmonary hypertension. Diabetes Metab Res Rev. 2019; 35(6):e3159.

46 Comorbidities of subjects affected by Corona virus-19 in Italy [Online]. Available from: https://www.epicentro.iss.it/coronavirus/ bolletino/Infografica [Accessed 2020 Jun 10].

47 Yang X, Yu Y, Xu J, Shu H, Xia J, Liu H, et al. Clinical course and outcomes of critically ill patients with SARS-CoV-2 pneumonia in Wuhan, China: a single-centred, retrospective, observational study. Lancet Respir Med. 2020;8(5):475-81.

48 Chen N, Zhou M, Dong X, Qu J, Gong F, Han $\mathrm{Y}$, et al. Epidemiological and clinical characteristics of 99 cases of 2019 novel corona virus pneumonia in Wuhan, China: a descriptive study. Lancet. 2020;395(10223):507-13. 
49 Richardson S, Hirsch JS, Narasimhan DO. Presenting characteristics, comorbidities, and outcomes among 5700 patients hospitalized with COVID 19 in the New York city Area. JAMA. 2020;323(20):2052-9.

50 Constatino S, Paneni F, Battista R, Castello L, Capretti G, Chiandotto S. Impact of glycemic variability on chromatin remodeling, oxidative stress, and endothelial dysfunction in patients with type 2 diabetes and with target HbA1c. Diabetes. 2017;66(9):2472-82.

51 El-Azeem IAA, Hamdy G, Amin M, Rashad A. Pulmonary function changes in diabetic lung. Egypt J Chest Dis. 2013;62(3):513-7.

52 Phillips BJ, Meguer JX, Redman J, Baker EH. Factors determining the appearance of glucose in the upper and lower respiratory tract secretions. Intensive Care Med. 2003;29(12): 2204-10.

53 Iqbal A, Prince LR, Novodvorsky P, Bernjak A, Thomas MR, Birch L, et al. Effect of hypoglycemia on inflammatory responses and the response to low-dose endotoxemia in humans. J Clin Endocrinol Metab. 2019;104(4): 1187-99.

54 Rodriguez-Guetierrez R, Gonzalez-Gonzalez JG, Zunga-Hernandez JA, McCoy RG. Benefits and harms of intensive glycemic control in patients with type 2 diabetes. BMJ. 2019; 367:15887.

55 Bode B, Garrett V, Messler J. Glycemic characteristics and clinical outcomes of COVID 19 patients hospitalized in the United States. J Diabetes Sci Technol. 2020;14(4):813-21.

56 Van Cromphaut SJ. Hyperglycaemia as part of the stress response: the underlying mechanisms. Best Pract Res Clin Anaesthesiol. 2009; 23(4):375-86.

57 Yang JK, Lin SS, Ji XJ, Guo LM. Binding of SARS coronavirus to its receptor damages islets and causes acute diabetes. Acta Diabetol. 2009;47(3):193-9.

58 Bornstein SR, Rubino F, Khunti K, Mingrone G, Hopkins D, Birkenfeld A. Practical recommendations for the management of diabetes in patients with COVID-19. Lancet Diabetes Endocrinol. 2020;8(6):546-50.

59 Batlle D, Soler MJ, Ye M. ACE2 and diabetes: ACE2 of ACEs. Diabetes. 2010;59(12):29946.

60 Wang F, Wang H, Fan J, Zhang Y, Wang H, Zhao Q. Pancreatic injury patterns in patients with COVID-19 pneumonia. Gastroenterology. 2020;159(1):367-37.

61 Carlsson PO, Berne C, Jansson L. Angiotensin II and the endocrine pancreas: effects on islet blood flow and insulin secretion in rats. Diabetologia. 1998;41(2):127-33.

62 Qin YY, Zhou YH, Lu YQ, Sun F, Yang S, Harypursat $V$, et al. Effectiveness of glucocorticoid therapy in patients with severe coronavirus disease 2019: protocol of a randomized controlled trial. China Med J. 2020;133(9): $1080-6$.
63 Russel CD, Miller JE, Baille JK. Clinical evidence does not support corticosteroid treatment for COVID-nCoV lung injury. Lancet. 2020;395(10223):473-5.

64 Yang JK, Feng Y, Yuan MY, Yuan SY, Fu HJ, $\mathrm{Wu} \mathrm{BY}$, et al. Plasma glucose levels and diabetes are independent predictors for mortality and morbidity in patients with SARS. Diabet Med. 2006;23(6):623-8.

65 Alhazzani W, Moller MH, Arabi YM, Loeb M, Gong MN, Fan E, et al. Surviving sepsis campaign: guidelines on the management of critically ill adults with coronavirus disease 2019 (COVID 19). Intensive Care Med. 2020;48(6): e440-69.

66 Ghosal S, Sinha B, Majumder M, Misra A. Estimation of effects of nationwide lockdown for containing coronavirus infection on worsening of glycosylated haemoglobin and increase in diabetes-related complications: a simulation model using multivariate regression analysis. Diabetes Metab Syndr. 2020; 14(4):319-23.

67 Zhu L, She ZG, Cheng X, Qin JJ, Zhang XJ, Cai $\mathrm{J}$, et al. Association of blood glucose control and outcomes in patients with COVID-19 and pre-existing type 2 diabetes. Cell Metab. 2020;31(6):1068-77.e3.

68 Zhou B, She J, Wang Y, Ma X. Utility of ferritin, procalcitonin, and $\mathrm{C}$-reactive protein in severe patients with 2019 novel coronavirus disease. 2020.

69 Cariou B, Hadjadj S, Wargny M, Pichelin M, Al-Salameh A, Allix I, et al. Coronavirus SARS-CoV2 and diabetes outcomes. Nantes University Hospital. Available from: https:// clinicaltrials.gov/ct2/show/NCT0434736.

70 Simonnet A, Chetboun M, Poissy J, Raverdy V, Noulette J, Duhamel A, et al. High prevalence of obesity in severe acute respioratory syndrome coronavirus-2 (SARS-CoV-2) requiring invasive mechanical ventilation. Obesity. $2020 \mathrm{Jul} ; 28(7): 1195-9$.

71 Sun Q, Li J, Gao F. New insights into insulin: the anti-inflammatory effect and its clinical relevance. World J Diabetes. 2014;5(2):89-96.

72 Serdu C, D’Onofrio N, Balestrieri ML, Barbieri M, Rizzo MR, Messina V, et al. Outcomes in patients with hyperglycemia affected by COVID-19: can we do more on glycemic control? Diabetes Care. 2020;43(7): 1408-15.

73 Shehav- Zaltzman G, Segal G, Konvalina N Tirosh A. Remote glucose monitoring of hospitalized, quarantined patients with diabetes and COVID 19. Diabetes Care. 2020;43(7): e75-6.

74 Sharma S, Ray A, Sadasivam B. Metformin in COVID-19: a possible role beyond diabetes. Diabetes Res Clin Pract. 2020;164:108183.

75 Buse LW, Chow JH, McCurdy MT, Khanna AK. Covid-19 and the RAAS-a potential role for angiotensin II. Editorial Crit Care. 2020; $24: 136$.
76 Gupta R, Hussain A, Misra A. Diabetes and COVID 19: evidence, current status and unanswered questions. Eur J Clin Nutr. 2020 Jun;74(6):864-70.

77 Romani-Perez M, Outeirino-Iglesias V, Moya CM. Activation of GLP-1 receptor by liraglutide increases ACE2 expression, reversing right ventricular hypertrophy, and improving the production of SP-A and SP-B in the lungs of type 1 diabetes rats. Endocrinol. 2015;156: 3559-69.

78 Tripathy D, Danielle G, Fiorentino TV, Perez-Cardena Z, Chavez-Velasquez A, Kamath S. Pioglitazone improves glucose metabolism and modulates skeletal muscle TIMP-3TACE dyad intype 2 diabetes mellitus: a randomized, double blind, placebo-controlled, mechanistic study. Diabetologia. 2013;56: 2153-63.

79 Zhang W, Xu YZ, Liu B, Wu R, Yang YY, Xiao XQ, et al. Pioglitazone upregulates angiotensin converting enzyme 2 expression in insulin-sensitive tissues in rats with high-fat diet-induced nonalcoholic steatohepatitis. ScientificWorldJournal. 2014 Jan 14;2014: 603409.

80 Kawanami D, Matoba K, Takeda Y, Nagai Y, Akamine T, Yokota T, et al. SGLT2 inhibitors as a therapeutic option for diabetic nephropathy. Int J Mol Sci. 2017;18(5):E1083.

81 Vishnu G. Phase 3 study valuating the efficacy and safety of dapagliflozin in respiratory failure in patients with COVID-19 (DARE-19). Retrieved from Clinicaltrials.gov identifier: NCT04350593. Completion date: 2020 Dec.

82 Rekedal LR, Massarotti E, Garg R, Bhatia R, Gleeson T, Lu B, et al. Changes in glycosylated hemoglobin after initiation of hydroxychloroquine or methotrexate treatment in diabetes patients with rheumatic diseases. Arthritis Rheum. 2010;62(12):3569-73.

83 Gerstein HC, Thorpe KE, Taylor DW, Haynes $\mathrm{RB}$. The effectiveness of hydroxychloroquine in patients with type 2 diabetes mellitus who are refractory to sulfonylureas: a randomized trial. Diabetes Res Clin Pract. 2002;55(3): 209-19.

84 Kumar V, Singh MP, Singh AP, Pandey MS Kumar S, Kumar S. Efficacy and safety of hydroxychloroquine when added to stable insulin therapy in combination with metformin and glimepiride in patients with type 2 diabetes compare to sitagliptin. Int J Basic Clin Pharmacol. 2018;7(10):1959-64.

85 Roque MR. Chloroquine and hydroxychloroquine toxicity. Medscape 2020.

86 Pal R, Bhadada SK. Should anti-diabetic medications be reconsidered amid COVID-19 pandemic? Diabetes Res Clin Pract. 2020;163: 108146.

87 Derwand R, Scholz M. Does zinc supplementation enhance the clinical efficacy of chloroquine/hydroxychloroquine to win today's battle against COVID-19? Med Hypotheses. 2020;142:109815.
COVID-19 and Diabetes Mellitus:

The Link and Clinical Implications
Dubai Diabetes Endocrinol J 2020;26:69-77 DOI: $10.1159 / 000511354$ 